\title{
Comparative study of gas accumulations in the Permian Changxing reefs and Triassic Feixianguan oolitic reservoirs between Longgang and Luojiazhai-Puguang in the Sichuan Basin
}

\author{
ZHAO WenZhi $^{1 *}$, XU ChunChun ${ }^{2}$, WANG TongShan ${ }^{3 *}$, WANG HongJun ${ }^{3}$, WANG ZeCheng ${ }^{3}$, \\ BIAN CongSheng ${ }^{3} \&$ LI Xia $^{3}$
}

\author{
${ }^{1}$ PetroChina Exploration \& Production Company, Beijing 100007, China; \\ ${ }^{2}$ PetroChina Southwest Oil \& Gas Field Company, Chengdu 610051, China; \\ ${ }^{3}$ PetroChina Research Institute of Petroleum Exploration \& Development, Beijing 100083, China
}

Received May 11, 2011; accepted June 30, 2011; published online August 30, 2011

\begin{abstract}
Reef and oolitic gas reservoirs in the Permian Changxing and Triassic Feixianguan formations have been discovered in both the Luojiazhai-Puguang and Longgang areas of the Sichuan Basin, but the accumulation scale, abundance and distribution patterns differ greatly. In fact, the two areas have more differences than they have similarities. Similarities include: (1) the lithology, properties and types of porosity of the reef and oolitic reservoirs are primarily consistent in the two areas; (2) well-developed regional caprocks that seal the fluid system; and (3) accumulation process histories, with liquid hydrocarbon charging at an early stage, cracking into gas at a high to over-mature stage, adjustment of gas reservoirs at an uplifting stage, and final reservoir generation at a late stage. Differences include: (1) gas accumulations in the Luojiazhai-Puguang area that are dominated by oil-type cracked gas, with multiple and sufficient gas sources, contrasting with gas accumulations in the Longgang area that are dominated by coal-sourced gas with insufficient gas sources; (2) heterogeneity and horizontal diversity of reservoirs in the Longgang area that are stronger than in the Luojiazhai-Puguang area; and (3) the development of deep and large faults in the Luojiazhai-Puguang area that link source, reservoir and migration pathways, contrasting with poorly developed faults in Longgang area, where laterally variable fractures are the major migration pathway. Because of these differences, abundant large-scale structurally-controlled gas accumulations are developed in the Luojiazhai-Puguang area, whereas lithology plays a more important role in gas accumulation in the Longgang area where accumulations are smaller-scale and have lower gas-bearing abundance. We suggest that future exploration for reef and oolitic gas accumulations should be strengthened in NE Sichuan and NW Sichuan Jiulongshan. In particular, the transitional zone between Longgang and Kaijiang-Liangping Bay has the best potential for new discoveries.
\end{abstract}

advantage transport of fault pathway, non-equilibrium transport of fracture pathway, integral accumulation with high abundance, heterogeneous accumulation with low abundance, Sichuan Basin

Citation: Zhao W Z, Xu C C, Wang T S, et al. Comparative study of gas accumulations in the Permian Changxing reefs and Triassic Feixianguan oolitic reservoirs between Longgang and Luojiazhai-Puguang in the Sichuan Basin. Chinese Sci Bull, 2011, 56: 3310-3320, doi: 10.1007/s11434-011-4668-8

Since high-production gas flows were obtained in the oolitic reservoirs of well Du-1 in the Permian Changxing Fm. and Triassic Feixianguan Fm. of the Sichuan Basin in 1995, a number of large- and medium-sized gas reservoirs have been discovered on both sides of Kaijiang-Liangping Bay, including large gas fields such as Dukouhe, Tieshanpo,

*Corresponding authors (email: zwz@ petrochina.com.cn; wts2007@petrochina.com.cn)
Luojiazhai, Puguang and Qilibei (each with proven reserves of over $300 \times 10^{8} \mathrm{~m}^{3}$ ) and gas-bearing structures such as Jinzhuping, Maobachang and Huanglongchang [1-4]. Highproduction industrial gas flows have been obtained in the reef reservoirs of the Changxing Fm. and the oolitic reservoirs of the Feixianguan Fm. in well LG1 drilled on the margin of the Longgang platform since 2006. Such production has been a prelude to reef and oolitic gas reservoir 
exploration in the Longgang area. Gas accumulations in reef and oolitic reservoirs in the Longgang and LuojiazhaiPuguang areas have more differences than similarities. A thorough understanding of the range of possible gas accumulations and distributions is of great significance to fostering strengths and circumventing weaknesses during gas exploration and development as well as enhancing the success ratio and benefits of exploration.

Through multi-disciplinary approaches such as natural gas geology, geochemistry and geophysics, this paper compares the similarities and differences of gas accumulation in reef and oolitic gas accumulations in the Changxing and Feixianguan formations of the Longgang and LuojiazhaiPuguang areas to develop representative accumulation and distribution models. This enables focusing of subsequent exploration in reef and oolitic bodies based on the differences, thereby driving growth in reef and oolitic body exploration.

\section{Geologic background}

The Sichuan Basin is a large petroliferous basin resulting from the superposition of a Paleozoic marine cratonic basin with deposition into a Mesozoic-Cenozoic continental foreland-intracontinental depression. Structurally, the Sichuan Basin can be divided into four secondary structural units [5-8] identifiable as Eastern, Central, Western and Southern Sichuan. The Longgang and Luojiazhai-Puguang areas are located at the junction of the Central and Eastern Sichuan structural units (Figure 1). Marine carbonate strata dominated deposition in the Sichuan Basin from the Sinian Period to the Middle Triassic Epoch. After the Late Triassic, the basin was enclosed by the uplift of peripheral mountains and deposits became continental clastic assemblages. Multiple super-thick sedimentary cycles developed in Sinian to Middle Triassic marine carbonate strata. The carbonate units experienced multiphase reformation and diagenesis, resulting in the formation of multiple source-reservoir-caprock assemblages during a lengthy history of development (Figure 2).

Reef and oolitic gas reservoirs previously discovered in the Changxing Fm.-Feixianguan Fm. of the Sichuan Basin mainly are distributed in the platform margin zone near Kaijiang-Liangping Bay. This zone has high prospectivity for gas exploration at present. Reef and oolitic gas reservoirs previously discovered in the Longgang and LuojiazhaiPuguang areas are located in the main body of platform margin zones on the southwestern and northeastern sides of the bay, respectively. The reservoirs discovered in the Longgang area are located in the gentle structural belt lying west of the Huayingshan fault zone, and those discovered in the Luojiazhai-Puguang area are located in the high and steep structural belt to the east of the same fault zone. The similarities and differences of the two areas, in terms of gas accumulation and their exploration significance, are discussed in detail in this paper.

\section{A comparative study of gas accumulation}

This study indicates that gas accumulations in reef and oolitic

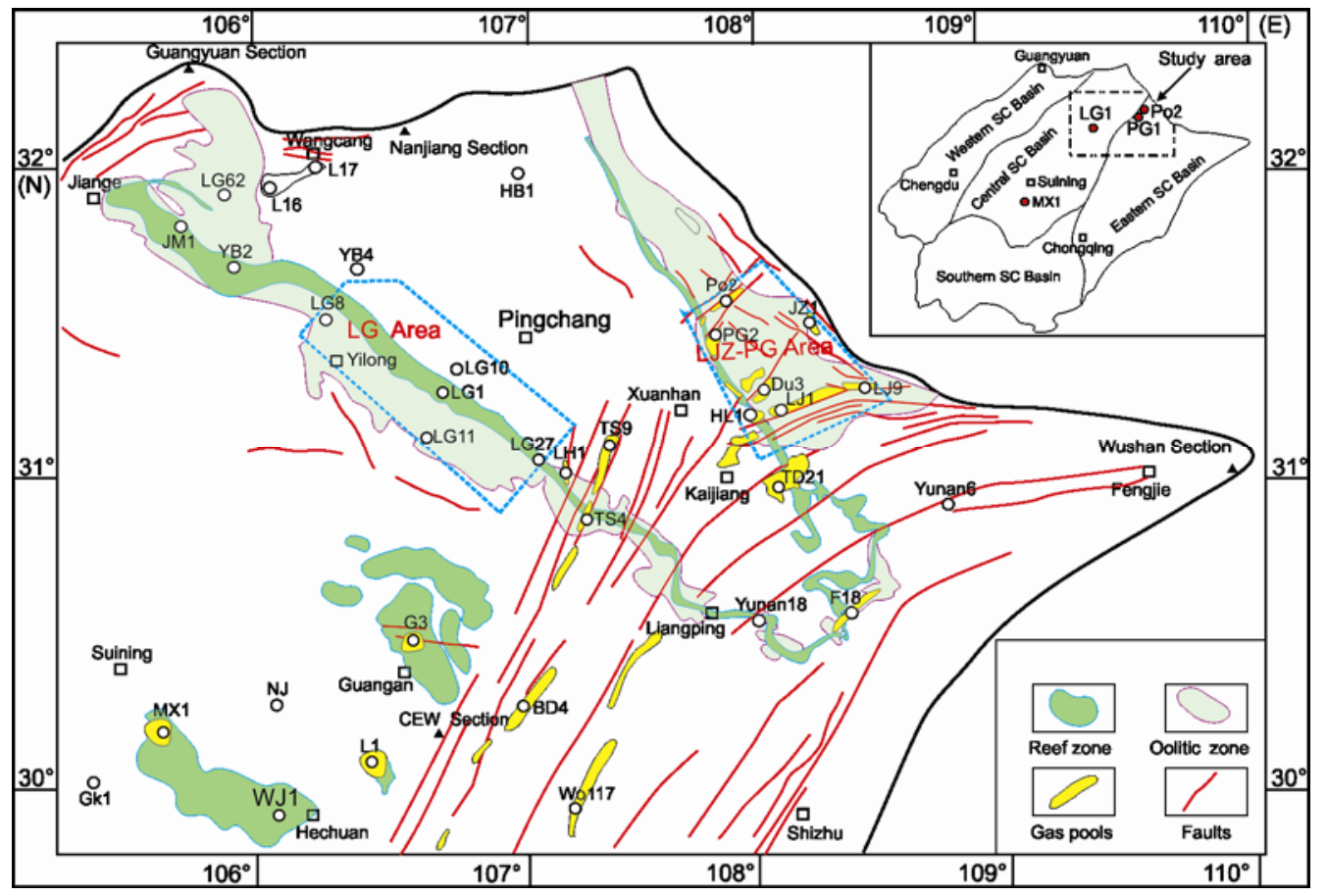

Figure 1 Sedimentary framework and structural location map of the Changxing Fm.-Feixianguan Fm. in the Longgang and Luojiazhai-Puguang areas. 


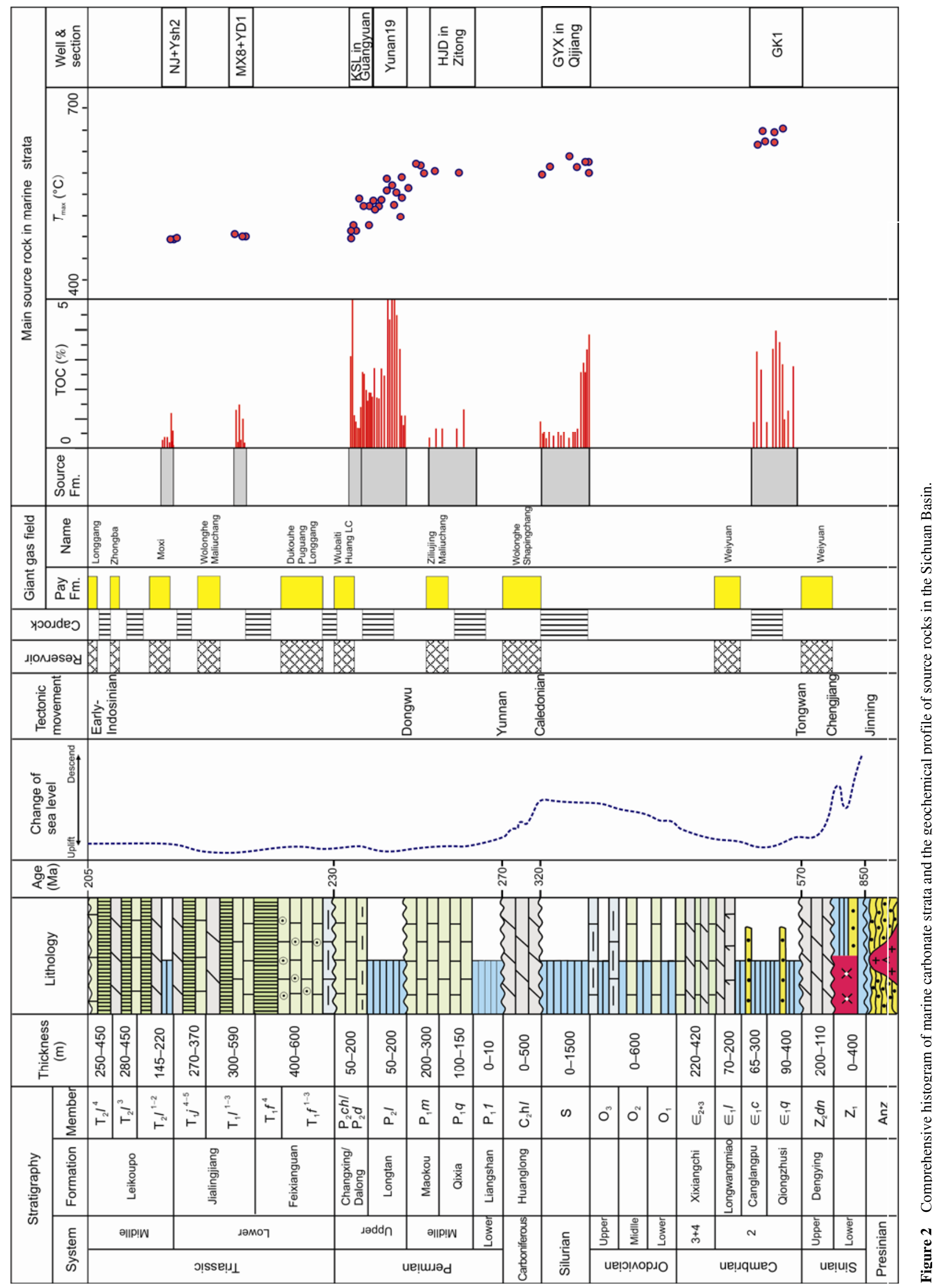


beach reservoirs in the Longgang and Luojiazhai-Puguang areas have more differences than similarities. However, three main similarities can be identified. (1) Reef and oolitic reservoirs in both areas are controlled by the high energy facies belts on the south and north sides of Kaijiang-Liangping Bay, with only slight changes in width and spatial location corresponding to variations in paleoenvironment and paleotopography at different geological periods. The lithologies and spatial types of the reef and oolitic reservoirs are similar, as are their other properties such as porosity and permeability, also have only slight differences. The oolitic reservoirs of the Feixianguan Fm. in the Longgang area have a porosity of $2 \%-12 \%$ (5.8\% on average) and a permeability of $0.06-223.7 \mathrm{mD}(27.7 \mathrm{mD}$ on average); the oolitic reservoirs of the Feixianguan Fm. in the Luojiazhai-Puguang area have a porosity of $2 \%-12 \%(7.8 \%$ on average) and a permeability of $0.01-446 \mathrm{mD}(54.4 \mathrm{mD}$ on average). (2) The two areas have similar sealing conditions. The gypsum rock units in the Lower Triassic Jialingjiang Fm. and Middle Triassic Leikoupo Fm. are thick (117-557 m), widely distributed, and act as the effective caprock for reef and oolitic gas accumulations in the two areas. The type and salinity of formation water also support the strong preservation conditions of the reef and oolitic series of strata in the two areas. (3) Both areas also experienced similar accumulation processes, with liquid hydrocarbon charging at an early stage, cracking into gas at a high to over mature stage, adjustment of gas reservoirs at an uplifting stage and final reservoir generation at a late stage. The homogenization temperatures of fluid inclusions in the reef and oolitic reservoirs in the Longgang and Luojiazhai-Puguang areas generally include three phases. The homogenization temperature for phase I was low $\left(<120^{\circ} \mathrm{C}\right)$, indicating liquid hydrocarbon inclusions and early charging of liquid hydrocarbons. The homogenization temperature for phase II was 130$150^{\circ} \mathrm{C}$, reflecting gas-liquid two-phase hydrocarbon inclusions as well as mixed charging of liquid hydrocarbons and their associated gas with gaseous hydrocarbons sourced from coal measures. The homogenization temperature for phase III was higher than $160^{\circ} \mathrm{C}$, indicating brine-bearing gas hydrocarbon inclusions. In addition, the Laser Raman detection result shows $\mathrm{H}_{2} \mathrm{~S}$-bearing high temperature gas hydrocarbon inclusions (dominated by methane) as well as liquid hydrocarbon pyrolysis and gas generation and accumulation events (a number of gas hydrocarbon inclusions containing no $\mathrm{H}_{2} \mathrm{~S}$ were developed in the Longgang area, reflecting generation and charging of hydrocarbons derived from coal measures). Tectonic activities in the Himalayan period caused gas reservoirs to be destroyed or reformed. Gas reservoirs were subsequently shaped after the Himalayan period.

In spite of the above similarities, the Longgang and Luojiazhai-Puguang areas are very different in the accumulation conditions and distribution of reef and oolitic gas reservoirs.

\subsection{Gas source conditions}

Oil-type cracked gas predominates in the Luojiazhai-Puguang area, coal-sourced gas predominates in the Longgang area, and the gas source sufficiency of the two areas is very different.

A total of four sets of main marine source rocks are developed in the Sichuan Basin. From bottom to top these are: the muddy shale of the Lower Cambrian Qiongzhusi Fm., the muddy shale of the Lower Silurian Longmaxi Fm., the carbonate units of the Lower Permian Qixia Fm.-Maokou Fm., and the muddy and coal series source rocks of the Upper Permian Longtan Fm. [9-12]. In addition, because of the stable environment and low energy of Kaijiang-Liangping Bay, the siliceous sediments and limy mudstones of the Dalong Fm., which correspond to the Permian Changxing Fm., are high-quality locally-distributed source rocks. The thickness, total organic carbon (TOC), maturity and organic matter type (Table 1) and accumulation contribution of the above source rocks differ widely in the Longgang and Luojiazhai-Puguang areas.

The gas-source correlation indicates that, oil-type cracked gas predominates in the reef and oolitic reservoirs in the Luojiazhai-Puguang area with multiple supply sources, whereas coal-sourced gas predominates in the Longgang area with sources mainly in the Upper Permian Longtan Fm. The source supply sufficiency is also very different in the two areas.

The gas component and its isotope characteristics are the direct basis for the determining the origin of the natural gas; the carbon isotope is the most effective and practical index [13-17]. According to the crossplot between natural gas $\delta^{13} \mathrm{C}_{1}-\delta^{13} \mathrm{C}_{2}$ (Figure 3), the origins of natural gas in reef and oolitic reservoirs in the Longgang and LuojiazhaiPuguang areas are different. The former is mainly coalformed gas and the latter is mainly oil-type gas. The natural gas $\delta^{13} \mathrm{C}_{1}$ and $\delta^{13} \mathrm{C}_{2}$ values in the Longgang area are mainly distributed in the range of $-28 \% 0_{-}-32 \%$ and $-21 \% 0^{-}-28 \%$ o respectively, with the main characteristics of coal-formed gas; whereas in local areas or intervals of the platform margin zone, the natural gas $\delta^{13} \mathrm{C}_{2}$ values are in the range of $-28.2 \%$ o- $-29.7 \%$, with oil-type gas present. The natural gas $\delta^{13} \mathrm{C}_{1}$ and $\delta^{13} \mathrm{C}_{2}$ values in the Luojiazhai-Puguang area are obviously lower. They mainly correspond to oil-type gas, with the values between those of the Longgang natural gas in reef and oolitic reservoirs and those of the natural gas in Carboniferous and Sinian (Figure 3). Considering that natural gas in the Carboniferous mainly comes from Silurian source rocks $[18,19]$ and natural gas in the Sinian mainly comes from the Cambrian [20-22], the deep source rocks such as those of the Silurian, Cambrian make great contributions to the gas accumulation of reef and oolitic reservoirs in the Luojiazhai-Puguang area, and the gas source sufficiency is far better than that in the Longgang area.

The solid bitumen within a reservoir can provide relevant 
Table 1 Geochemical characteristics of marine source rock in the Longgang and Luojiazhai-Puguang areas a)

\begin{tabular}{|c|c|c|c|c|c|c|}
\hline Strata & Location & Thickness (m) & TOC $(\%)$ & $R_{\mathrm{o}}(\%)$ & $\delta^{13} \mathrm{C}(\% \circ)$ & Type \\
\hline $\mathrm{P}_{2} d$ & Bay area & $10-30$ & $1.0-8.5$ & $1.6-1.8$ & $-26--28.5$ & II \\
\hline \multirow{2}{*}{$\mathrm{P}_{2} l$} & Longgang area & $40-80$ & $2.0-3.0$ & $2.0-2.8$ & $-23.2--27$ & II, III \\
\hline & Luojiazhai-Puguang area & $120-160$ & $3.0-5.0$ & $2.5-3.2$ & $-26.9--29.4$ & II \\
\hline \multirow{2}{*}{$\mathrm{P}_{1} q-m$} & Longgang area & $0-50$ & $0-1.0$ & $2.2-2.5$ & \multirow{2}{*}{$-26--30.5$} & \multirow{2}{*}{ I, II } \\
\hline & Luojiazhai-Puguang area & $100-150$ & $0-1.0$ & $2.6-3.2$ & & \\
\hline \multirow{2}{*}{$\mathrm{S}_{1} l$} & Longgang area & $10-20$ & $0-0.5$ & $2.4-2.8$ & \multirow{2}{*}{$-28--32$} & \multirow{2}{*}{ I, II } \\
\hline & Luojiazhai-Puguang area & $40-60$ & $2.0-5.0$ & $3.2-3.8$ & & \\
\hline \multirow{2}{*}{$€_{1} q$} & Longgang area & $10-20$ & $0.5-1.0$ & $3.0-3.5$ & \multirow{2}{*}{$-30--34.9$} & \multirow{2}{*}{ I } \\
\hline & Luojiazhai-Puguang area & $40-60$ & $1.0-1.5$ & $3.5-4.0$ & & \\
\hline
\end{tabular}

a) The data listed in the table come from 54 source rock samples tested in this paper and [11].

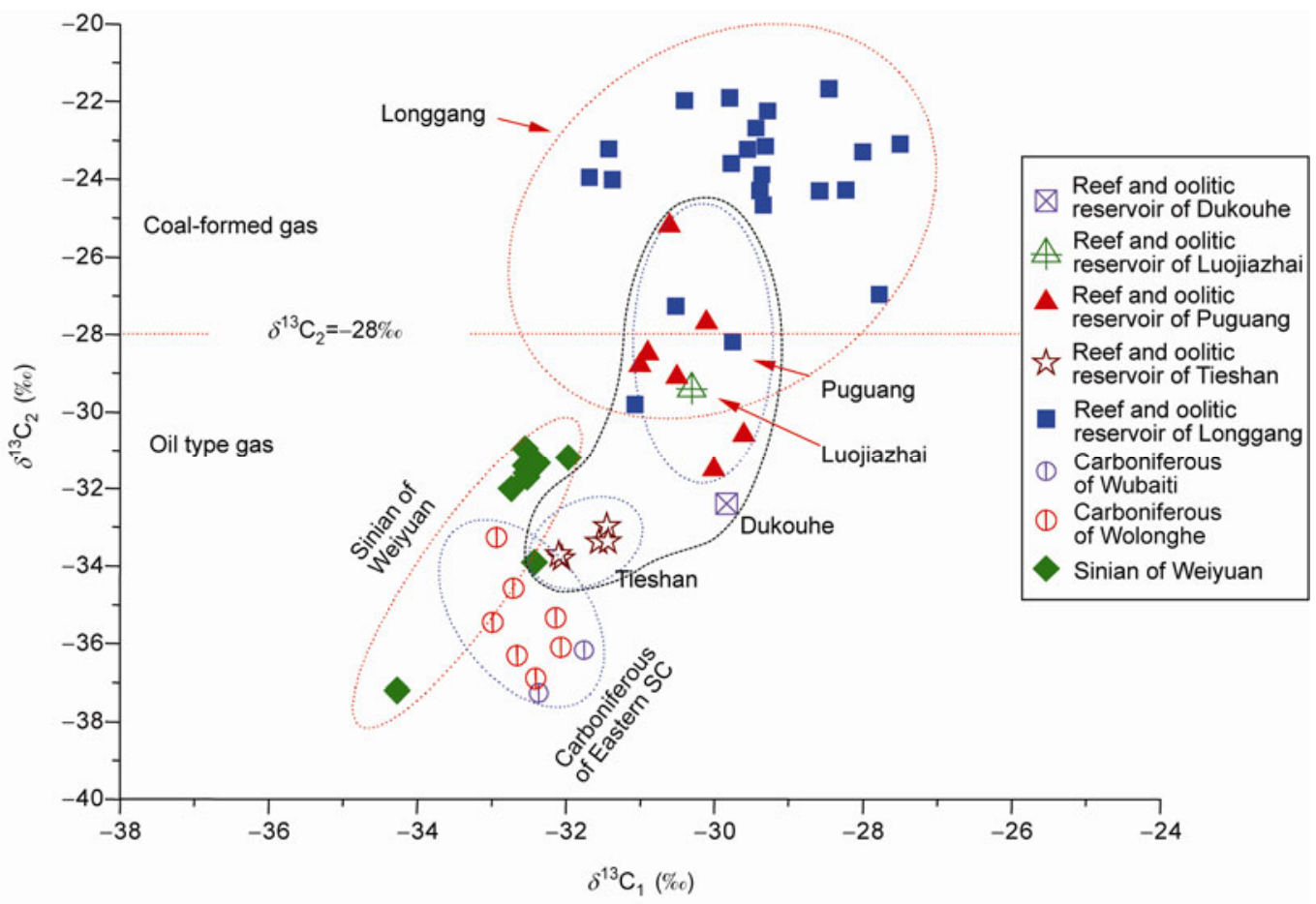

Figure 3 Origin comparison of natural gas in reef and oolitic reservoirs and other reservoirs in the Sichuan Basin.

information on gas origin. The solid bitumen in the reef and oolitic reservoirs of the Luojiazhai-Puguang area is pyrobitumen derived from the pyrolysis of liquid hydrocarbon [23], which is the cracked product of paleo-oil reservoirs and also an important basis for identification of oil-type cracked gas. Solid bitumen in reef and oolitic reservoirs of the platform margin zone in the Longgang area is angular and flaky, rimmed and spherulitic under a microscope, with a high bitumen reflectance $(\mathrm{Rb} \%)$ of $2.2 \%-3.2 \%$. The average carbon isotope of bitumen $\left(\delta^{13} \mathrm{C}\right)$ is $-29.0 \%$, corresponding to a pyrobitumen of thermal genesis derived from a sapropelic type source; the solid bitumen developed in intraplatform reef and oolitic reservoirs in the Longgang area is eroded bitumen with a low bitumen reflectance $(\mathrm{Rb} \%)$ of only $0.92 \%$. The carbon isotope of the bitumen $\left(\delta^{13} \mathrm{C}\right)$ is on average $-26.2 \%$, reflecting a humic type origin for the source without thermal cracking. Therefore, according to the comprehensive identification of solid bitumen in reservoir and natural gas $\delta^{13} \mathrm{C}_{1}$ and $\delta^{13} \mathrm{C}_{2}$, reef and oolitic reservoirs in the Luojiazhai-Puguang area are dominated by oil-type cracked gas; the Longgang platform margin zone is dominated by coal-sourced gas but with a portion of oiltype gas contributing; and the Longgang intra-platform zone has only coal-sourced gas accumulation.

According to the accumulative time effect of argon isotopes, the value of ${ }^{40} \mathrm{Ar} /{ }^{36} \mathrm{Ar}$ can be used to estimate the age of natural gas source rocks [24-26]. The natural gas ${ }^{40} \mathrm{Ar} /{ }^{36} \mathrm{Ar}$ in Puguang gas field was measured by previous researchers [11]. The value of ${ }^{40} \mathrm{Ar} /{ }^{36} \mathrm{Ar}$ was found to range from 1280 to 1690 , which reflects that the gas source age 
ranges from $383 \mathrm{Ma}$ (Later Devonian Period) to $323 \mathrm{Ma}$ (Earlier Carboniferous Period). However, these two sets of source rocks in the Sichuan Basin are absent, so the test results are inconsistent with geologic conditions. A more reasonable explanation is that the natural gas in oolitic reservoirs should come from several sets of source rocks, which were deposited prior to $383 \mathrm{Ma}$ (Cambrian and Silurian) and more recently than $323 \mathrm{Ma}$ (Carboniferous), instead of a single source. This can provide important evidence to constrain deep gas sources and hydrocarbon systems in the Cambrian, Silurian and other units to reef and oolitic reservoirs in the Luojiazhai-Puguang area.

Gas source rocks can also be identified with the carbon isotope fractionation variation index. The $\delta^{13} \mathrm{C}_{2}$ value of natural gas is $1 \% 0^{-2} \%$ o lower than that of kerogen $[27,28]$, whereas the $\delta^{13} \mathrm{C}$ value of solid bitumen is consistent with that of kerogen [29,30]. In the Longgang area, the $\delta^{13} \mathrm{C}$ value of ethane gas is heavier as a whole, and if subtracting $1 \%$ - $2 \%$ of fractionation degree, it corresponds to the kerogen $\delta^{13} \mathrm{C}$ value of Upper Permian gas source rocks. This shows the characteristics of the coal-formed gas. However, this is locally mixed with oil-type gas, which may originate from the more sapropelic type gas source rocks of the Dalong and Longtan Fms. In the Luojiazhai-Puguang area, the $\delta^{13} \mathrm{C}$ value of ethane gas is widely distributed. This is related to several sets of gas source rocks from the Upper Permian Dalong and Longtan Fms., the Lower Permian, the Silurian and the Cambrian. In particular, the natural gas in the reef and oolitic reservoirs of the Dukouhe and Tieshan gas fields is closely related to Silurian and Cambrian source rocks. Note that compared with other source rocks, Cambrian source rocks have a different contribution approach to reef and oolitic reservoirs in the Luojiazhai-Puguang area, because solid bitumen in these reef and oolitic reservoirs have no relation with Cambrian source rocks. As a result, natural gas sourced from Cambrian rocks at a high to over mature stage is derived mainly from the thermal cracking of dispersed liquid hydrocarbon remaining in the source rocks. The solid bitumen is a residue of cracked liquid hydrocarbon in paleo-oil reservoirs from Upper Permian and Silurian source rocks.

\subsection{Transport conditions}

Advantageous transport along fault pathways predominate in the Luojiazhai-Puguang area, non-equilibrium transport along fracture pathway predominates in the Longgang area, and the fullness and scale of gas reservoirs greatly differ.

The Luojiazhai-Puguang area is located at the junction of the northern part of the high and steep structural belt in eastern Sichuan and the faulted fold belt of Daba Mountain. The region has large structural relief and has developed two groups of faults oriented roughly NE-SW and NW-SE (Figure 1). The throw and extent of the faults are relatively large, faulted downwards to the Ordovician and Cambrian and disappearing upwards in the Middle Triassic Jialingjiang and Leikoupo Fms. Several sets of source rocks are in communication with these large faults, and periods of past fault activity match well with the periods of hydrocarbon expulsion from source rocks [31,32]. As a result, an advantageous fault pathway transport system is in place that provides favorable gas source supply and transport conditions.

The Longgang area is located on a generally monoclinal background with little structural relief. Faults in this area are few, small in scale, and those that exist mainly connect through the Longtan Fm.-Changxing Fm. The natural gas transport system consists mainly of non-equilibrium fractures. Therefore, reservoir blocks and intervals differ greatly in saturation due to variation in direct contact with source rocks. Due to the lack of larger scale faults, it is difficult for reef and oolitic reservoirs in the Longgang area to connect to deep source rocks such as in the Lower Permian, Silurian, and Cambrian, and as a result, most natural gas comes from Upper Permian source rocks. The gas source supply and dominant transport conditions are inferior to those in the Luojiazhai-Puguang area, so the saturation and scale of gas reservoirs are relatively poor. The saturation of gas reservoirs in the Longgang area (averaging 68.3\%) is generally less than that in the Luojiazhai-Puguang area (averaging 94.6\%). Because the Changxing Fm. is in a more favorable position closer to the Longtan Fm. source rocks, the saturation (averaging 78\%) of gas reservoirs there is higher than for that of the Triassic Feixianguan Fm. (averaging 58.3\%). Therefore, the possibility of hydrocarbon accumulation in a Changxing Fm. reef body is higher than that in the Feixianguan Fm.

In addition to connecting source rocks and reservoirs, the faults can also play a constructive role in the formation of reservoirs. The formation of diagenetic pores in carbonate rocks often requires fluid flow to carry material needed to promote the occurrence of dolomitization and burial corrosion. [33,34]. The large-scale faults in the Luojiazhai-Puguang area can provide good pathways for the migration of diagenetic material; therefore, the quality of reef and oolitic reservoirs in this area is better than in the Longgang area.

\subsection{Reservoir conditions}

The reservoirs in the Luojiazhai-Puguang area have a substantial length scale and continuity; the reservoirs in the Longgang area are heterogenous and vary laterally.

There are slight differences in the thickness and physical property conditions of the reef and oolitic reservoirs in the Longgang and Luojiazhai-Puguang areas, but their extent and horizontal continuity greatly differ. Therefore, the scales of gas reservoirs and gas-water heterogeneity also vary greatly.

The scales of oolitic beach bodies in the Feixianguan Fm. of the Luojiazhai-Puguang area are greatly affected by sedimentary paleoenvironment and they change continuously with variations in sea level. Oolitic reservoirs are 
distributed in a NE-SW orientation, generally extending over $10 \mathrm{~km}$, but with an average extent of $17.8 \mathrm{~km}$, and a maximum width in the Luojiazhai-Gunziping area of $33 \mathrm{~km}$. The reef reservoirs in the Changxing Fm. are 5-8 km long in general ( $6.9 \mathrm{~km}$ on average). In addition, the spatial location of reef reservoirs is not completely consistent with that of oolitic beach reservoirs, and most platform margin reef and oolitic bodies are not superposed in the LuojiazhaiPuguang area except those in the Puguang gas field.

Reef and oolitic beach zones in the Longgang area are narrower than those in the Luojiazhai-Puguang area, which extend in a NW-SE direction with lengths less than $10 \mathrm{~km}$ in general and $5.6 \mathrm{~km}$ on average. The reef and oolitic reservoirs are distributed in thin alternate layers longitudinally, and their horizontal extent is small. For instance, Wells LG1, LG001-3 and LG2 are less than $5 \mathrm{~km}$ from one another, whereas the reservoirs in the Changxing Fm. are not interconnected, and have a system of their own transversely. They show multiple sets of reservoirs superposed and cut by tight zones longitudinally, which have multiple gas-water contacts and multiple pressure systems and present a pattern of "One Reef, One Beach, One Reservoir", with a very complex gas and water distribution.

\subsection{Type and distribution of gas reservoirs}

Structural gas reservoirs predominate in the LuojiazhaiPuguang area; lithologic control is most important in the Longgang area, where lateral heterogeneity is stronger.

Statistics show that the scale of gas reservoirs formed by reef and oolitic beach bodies in the Luojiazhai-Puguang area is relatively large on the whole, where trap height is generally over $500 \mathrm{~m}$, and the abundance and saturation of gas reservoirs are both high (the abundance is greater than $8.4 \times 10^{8} \mathrm{~m}^{2} / \mathrm{km}^{2}$ on average, and the trap saturation averages 94.6\%). Regionally, the high abundance of traps occurring in the Luojiazhai-Puguang area corresponds to a mediumto-large integrated accumulation of hydrocarbons (Figure 4a). In the Longgang area, the structures are gentler. The vertical extent of gas reservoirs here is generally less than $100 \mathrm{~m}$. The lack of substantial faults and structures means that traps are generally controlled by lithology, and structural- lithologic gas reservoirs predominate (Figure 4b). The abundance of the gas reservoirs in the Longgang area, $2.6 \times 10^{8} \mathrm{~m}^{3} / \mathrm{km}^{2}$, is lower than that in the LuojiazhaiPuguang area, and the saturation of the traps is only $68.3 \%$ on average. Lithologically controlled gas reservoirs are observed to be assembled on a monoclinal background.

\subsection{Basic law of gas accumulation and distribution}

As mentioned previously, gas accumulation in reef and oolitic reservoirs in the Longgang and Luojiazhai-Puguang areas have more differences than similarities. Correspondingly, the characteristics and distributions of gas reservoirs in the two areas also differ. Further exploration will benefit from an improved understanding of these differences. The following investigations and discussion establish the basic principles of gas accumulation and distribution in the Longgang and Luojiazhai-Puguang areas, thereby providing guidance for subsequent exploration and development.

(i) Formation and distribution of reef and oolitic gas enrichment zones is controlled by the three-in-one assemblage of "source rock-reservoir-transportation pathway"; the paragenesis of plentiful gas sources and advantageous transport systems with large traps causes the formation and distribution of large gas reservoirs.

As mentioned previously, due to being cut by large deep faults in the Luojiazhai-Pugung area, multiple sets of highquality Permian, Silurian and even Cambrian source rocks have been interconnected, plentiful gas sources have been provided, saturation of traps is good, the superposition of high-quality dolomite reservoirs with high and steep structures has formed large traps, and the monomer scale of the formed gas reservoir is large (Figure 5). Statistics show that the size of the reef gas reservoirs in the Permian Changxing Fm. in the Luojiazhai-Pugung area is $32.9 \times 10^{8}$ to $387 \times 10^{8}$ $\mathrm{m}^{3}$. The size of the oolitic beach gas reservoirs in the Feixianguan $\mathrm{Fm}$. is $26.9 \times 10^{8}$ to $581 \times 10^{8} \mathrm{~m}^{3}$, with an average for their main bodies of $183 \times 10^{8} \mathrm{~m}^{3}$-over three times larger than the average in the Longgang area.

Reef and oolitic reservoirs are extensively distributed in the gentle structural setting of the Longgang area. These reservoirs, especially the reef reservoirs of the Permian
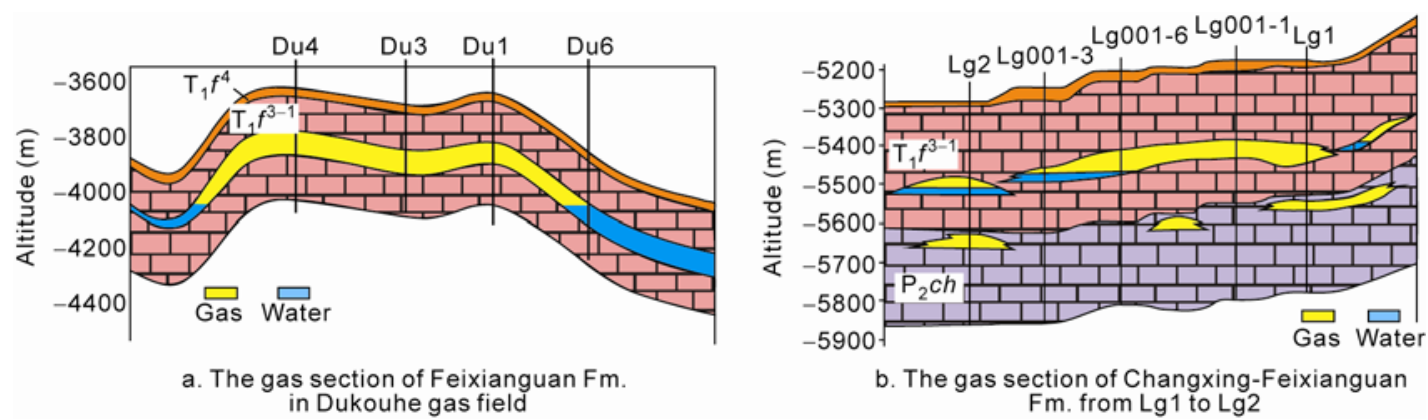

Figure 4 Reef and oolitic gas reservoir profiles of the Changxing Fm.-Feixianguan Fm. in the Longgang and Luojiazhai-Puguang areas. 


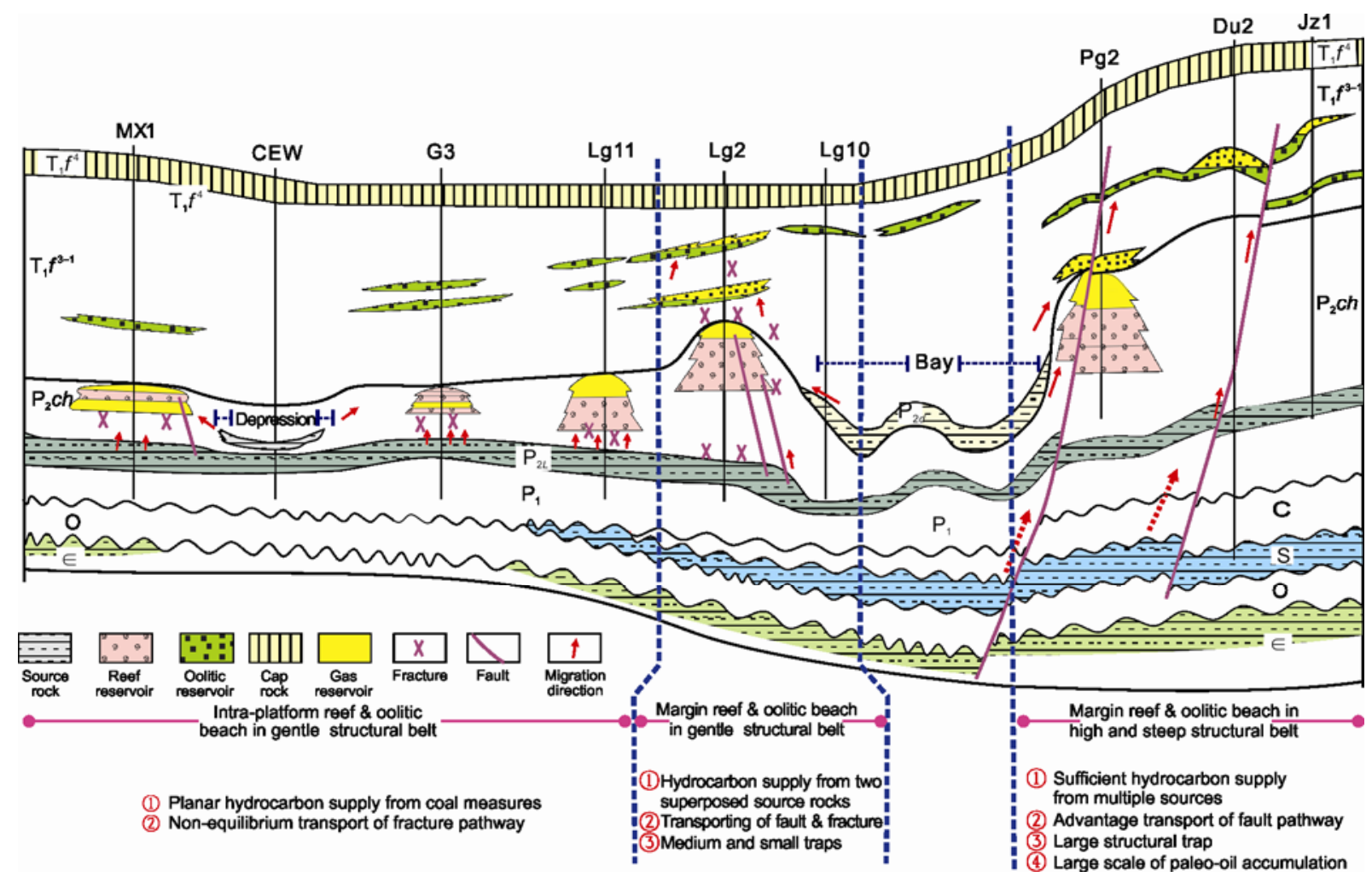

Figure 5 Pattern of accumulation and distribution in reef and oolitic reservoirs in the Sichuan Basin.

Changxing Fm., are conveniently and extensively juxtaposed with the underlying coal measure source rocks of the Longtan Fm. (Figure 5). This should provide a favorable source-reservoir assemblage; however, a set of compact strata separates the lower part of the reef reservoir from the source rocks. Therefore, if there is no fault or fracture to connect them, the probability of accumulation will be reduced, and the filling of reef and oolitic reservoirs could be selective and heterogeneous. The reservoirs with established connections with source rocks via fractures and faults have larger opportunities for accumulation than assemblages with poor connectivity .

(ii) Reef and oolitic reservoirs near faults and main fracture zones have higher probabilities of bearing gas and larger scale gas reservoirs

A statistical analysis (Table 2) of gas reservoir characteristics in the Longgang and Luojiazhai-Puguang areas indicates that reef and oolitic reservoirs connected to or adjacent to large faults or major facture zones have a greater probably of bearing oil. Additionally, they are likely to be larger in scale and more saturated. Most high-quality reef and oolitic gas reservoirs in the Luojiazhai-Puguang area correspond to large deep faults, the probability of gas in the reservoirs is high (over $80 \%$ in general), and the average saturation is around $90 \%$. The probability of gas in reservoirs with fractures in the Longgang area is also high (averaging $61.2 \%$ ), but both the ratio and saturation of the reservoirs are worse than those of reservoirs in the Luojia-
zhai-Puguang area.

(iii) Planar evaporative hydrocarbon supply and nonequilibrium transport via fractures result in large-scope accumulations that are limited in scale; the probability of accumulation in effective reservoirs without an adequate source supply is poor.

The so-called "planar evaporative type" of hydrocarbon supply refers to source rocks that lie below and in direct contact with reservoirs above, with a large contact area and spatial scope. Driven by buoyancy or source-reservoir pressure difference, the natural gas from source rocks migrates towards the reservoirs in planar evaporative mode. This is the basic form of source-reservoir transportation for areally large gas accumulations. Gas source rocks in the Longtan Fm. and reef and oolitic reservoirs in the Longgang area provide such accumulation conditions. However, the following two conditions limit large-area gas accumulations in this area: (1) isolated mottling-type distributions of reef reservoirs and (2) the existence of a tight barrier between the lower part of reef reservoirs and source rocks. These two factors therefore require at least one of the following two conditions for gas to accumulate in reef and oolitic reservoirs in the Longgang area: (1) the development of a "leakage skylight" in the tight barrier between reef reservoirs and source rocks, or (2) the establishment of a connection between source rocks and reservoirs via faults and fractures. The two factors result in non-equilibrium gas accumulations in the Longgang area, with large horizontal 
Table 2 Correlation between the scale and gas-bearing probability of reef and oolitic reservoirs and faults and fractures in the Longgang (B) and Luojiazhai-Puguang (A) areas ${ }^{\text {a) }}$

\begin{tabular}{|c|c|c|c|c|c|c|c|c|c|c|}
\hline Area & Strata & Gas field & $\begin{array}{c}\text { Reserve } \\
\text { abundance } \\
\left(10^{8} \mathrm{~m}^{3} \mathrm{~km}^{-2}\right)\end{array}$ & $\begin{array}{l}\text { Fullness } \\
\text { (\%) }\end{array}$ & $\begin{array}{l}\text { Source } \\
\text { fault }\end{array}$ & $\begin{array}{c}\text { Density of } \\
\text { fracture } \\
\text { (bar/m) }\end{array}$ & $\begin{array}{c}\text { Transporting } \\
\text { pathway }\end{array}$ & $\begin{array}{l}\text { Number of } \\
\text { reservoir wells }\end{array}$ & $\begin{array}{l}\text { Number of } \\
\text { gas wells }\end{array}$ & $\begin{array}{c}\text { Gas bearing } \\
\text { probability } \\
(\%)\end{array}$ \\
\hline \multirow{9}{*}{ A } & \multirow{6}{*}{$\mathrm{T}_{1} f$} & Dukouhe & 10.6 & 94.6 & Connect $\epsilon_{1}$ & $1.8-6.2$ & \multirow{8}{*}{$\begin{array}{l}\text { Large and } \\
\text { deep fault }\end{array}$} & \multirow{6}{*}{40} & \multirow{6}{*}{32} & \multirow{6}{*}{80} \\
\hline & & Tieshanpo & 15 & 86.6 & Connect $\epsilon_{1}$ & $3.9-13$ & & & & \\
\hline & & Luojiazhai & 7.6 & 100 & Connect $\mathrm{C}_{1}$ & 21.8 & & & & \\
\hline & & Jinzhuping & 2.3 & 100 & Connect $\epsilon_{1}$ & 20.1 & & & & \\
\hline & & Gunziping & 7.3 & 48.5 & Connect S & 16.4 & & & & \\
\hline & & Qilibei & 7.7 & 92.8 & Connect $\epsilon_{1}$ & $1.5-4.6$ & & & & \\
\hline & \multirow{2}{*}{$\mathrm{P}_{2} c h$} & Huanglongchang & 2.6 & 100 & Connect O & 6.7 & & \multirow{2}{*}{15} & \multirow{2}{*}{13} & \multirow{2}{*}{86.6} \\
\hline & & Qilibei & 5.1 & 88.1 & Connect $\epsilon_{1}$ & $1.3-2.0$ & & & & \\
\hline & \multicolumn{2}{|c|}{ Main body average } & 8.4 & 94.6 & & & & & & 83.3 \\
\hline \multirow{12}{*}{ B } & \multirow{4}{*}{$\mathrm{T}_{1} f$} & LG2 & 3.6 & 51 & None & $2.5-7$ & \multirow{11}{*}{$\begin{array}{l}\text { Small fault } \\
\text { and fracture }\end{array}$} & \multirow{4}{*}{18} & \multirow{4}{*}{10} & \multirow{4}{*}{55.6} \\
\hline & & LG 1 & 5.8 & 61 & Connect P & $5.9-9$ & & & & \\
\hline & & LG 26 & 2 & 73 & None & $2.0-4.5$ & & & & \\
\hline & & LG 6 & 2.3 & 48 & None & $4.2-6.7$ & & & & \\
\hline & \multirow{7}{*}{$\mathrm{P}_{2} c h$} & LG 8 & 1.4 & 76 & None & $0.2-1.2$ & & \multirow{7}{*}{18} & \multirow{7}{*}{12} & \multirow{7}{*}{66.7} \\
\hline & & LG 2 & 1.6 & 41 & None & $2.5-7$ & & & & \\
\hline & & LG 1 & 5.1 & 100 & Connect P & $5.9-9$ & & & & \\
\hline & & LG 28 & 4 & 79 & None & $0.2-2.0$ & & & & \\
\hline & & LG 26 & 3.8 & 49 & None & $2.0-4.5$ & & & & \\
\hline & & LG 27 & 2.6 & 100 & Connect P & $3.6-8.6$ & & & & \\
\hline & & LG 11 & 2.5 & 100 & None & $0.2-1.5$ & & & & \\
\hline & \multicolumn{2}{|c|}{ Main body average } & 2.6 & 68.3 & & & & & & 61.2 \\
\hline
\end{tabular}

a) (1) Main body average value is obtained by removing the individual monomers and reflecting the overall situation. (2) Gas-bearing probability is the ratio of the number of gas wells to the number of wells drilled to reservoirs.

variability. The planar evaporative type hydrocarbon supply and non-equilibrium transport via fractures and faults, as mentioned above, can result in a large scope for accumulation but lower abundance and greater reservoir heterogeneity in general.

\section{Significance}

This comparative study has revealed that the gas accumulations in reef and oolitic reservoirs in the Longgang and Luojiazhai-Puguang areas are more different than similar. The differences involve such subjects as the main controls on accumulation, the scale of accumulation, and the distribution of gas reservoirs in the two areas. The assessment of these differences has great significance in the promotion of research into gas accumulation and the development of gas fields in the region.

\subsection{Gas accumulation in reef and oolitic reservoirs controlled by: fault transport, supply of source material, and the sedimentary facies of the reef and oolitic beach deposits}

Large deep faults and high steep structures are developed in the eastern and northeastern parts of the Sichuan Basin, where they can advantageously act as hydrocarbon transport pathways. In addition, the effective three-dimensional alignments of faulted anticlines with high-quality reef and oolitic reservoirs combined with a sufficient supply of gas from multiple sets of source rocks results in favorable conditions for high-efficiency gas accumulation and the formation of medium-to-large sized gas reservoirs. East of the Longgang and Liangping areas and west of Tieshanpo, favorable accumulation zones are predicted. Intra-platform reef and bioclastic beach reservoirs of the Changxing Fm. are distributed extensively in the central Sichuan Basin where they are in planar contact with coal measure source rocks of the Longtan Fm. Where fractures are present that enable gas transport, natural gas is preferably charged towards the Changxing Fm. The scale of gas accumulations in the Changxing Fm. is not always large, but the probability of accumulation will certainly be higher than that of the Feixianguan Fm. The latest studies show that intra-platform reef and oolitic bodies are associated with the ancient highlands in the initial sedimentary stage. Paleostructure studies indicate that these initial sedimentary highlands are all related to bedrock paleohighs. In addition, these paleohighs are closely related to the activities of basement faults. Therefore, it is predicted that the intra-platform reef and 
bioclastic beach bodies associated with basement faults and paleohighs should match well with traps in terms of gas transport and physical reservoir properties. Also, they should have the potential and prospect of scaled accumulation.

\subsection{Sedimentary facies changes and the migration of reef and oolitic bodies in time and space result in near-source gas accumulations}

The Dalong Fm. in the region of Kaijiang-Liangping Bay is isochronous and different face with the Changxing Fm. The formation undergoes lateral facies change into a set of high quality source rocks. Due to the migration of oolitic beach bodies, a near-source "lower generating and upper preserving" gas accumulation was formed by the juxtaposition of oolitic reservoirs with the Dalong Fm. source rock. Potential for accumulation is high as long as good reservoirs are developed between the platform margin zones and low energy sedimentary facies in the bay. The reservoirs on the windward side, facing the bay on the platform margin, have a similar accumulation assemblage to that found in the LG1LG2 area, which is close to that of the Dalong Fm. source rocks. Effective accumulation can be formed as a result of fault transport. Present exploration and associated studies indicate that the oolitic beach units of the Feixianguan Fm. vary widely from Members I to III. They advance from the platform margin to the bay, and can even extend to the early bay region where they connect with the Dalong Fm. source rock. The extent of the oolitic beach reservoirs of the Feixianguan Fm. in both the Longhuichang and Tieshan areas can exceed $10 \mathrm{~km}$ in regions where industrial gas reservoirs have been discovered. The latest seismic data show a wide distribution of oolitic beach reservoirs in JianmenJiulongshan and northwestern Sichuan where the extent of the oolitic beach towards the bay is comparatively long. Accumulation conditions are similar to those of the Feixianguan Fm. in the LG1-LG2 area. Therefore, low-relief structural zones near the bay that are associated with faults should have good prospectivity and be worthy of in-depth study.

\section{Conclusions and suggestions}

\subsection{Conclusions}

(i) The basic factors controlling gas accumulations in the Longgang and Luojiazhai-Puguang areas are more different than similar. Differences include: (1) gas accumulations in the Luojiazhai-Puguang area that are dominated by oil-type cracked gas, in comparison to gas accumulations in the Longgang area that are dominated by coal-formed gas, thereby resulting in significant differences in the availability of gas sources; (2) the domination of gas transport by faults in the Luojiazhai-Puguang area compared with non-equilibrium transport via fractures in the Longgang area, thereby resulting in great differences in gas saturation and the scale of reservoirs in the two areas; (3) stronger heterogeneity and horizontal diversity of reef and oolitic reservoirs in the Longgang area as compared with the Luojiazhai-Puguang area, with correspondingly smaller scales and continuity; and (4) the domination of abundant, large-scale structural gas reservoirs in the Luojiazhai-Puguang area, compared with lithologically controlled reservoirs in the Longgang area, with greater lateral variability and heterogeneity.

(ii) The basic rules for gas accumulation and distribution in the region can be summarized as follows. (1) The formation and distribution of gas enrichment zones is controlled by three-in-one "source rock-reservoir-transportation pathway" assemblages, the paragenesis of plentiful gas sources, and advantageous transportation systems with large traps leading to the forming and distribution of large gas reservoirs. (2) Reef and oolitic bodies near faults and main fracture zones have a high probability of bearing gas in large gas reservoirs. (3) A planar evaporative type of hydrocarbon supply combined with the non-equilibrium transport of gas via fractures results in a large scope for accumulation but a limited accumulation scale. As a result, the probability of the accumulation of effective reservoirs without a source supply is poor.

\subsection{Suggestions}

(i) There is a large difference in the environment of formation of Permian reef and Triassic oolitic beach deposits in the Sichuan Basin. Although the two reservoir units are somewhat consistent with each other in terms of the geographical locations where they are found, they should be studied separately. Based on fine-scale three-dimensional characterizations of paleogeography and paleoenvironment, and variations in the styles of hydrocarbon inheritance and migration for the two areas can be summarized.

(ii) The study of sedimentary microfacies constrained by isochronous sequences and governed by rules concerning the distribution of reef and oolitic beach sequences should be strengthened by means of techniques related to, for example, outcrop-, downhole-, or seismic inversion-based studies. Recognizing that gas accumulations are controlled by three-in-one assemblages of "source rock-reservoirtransportation pathway", extended studies should be conducted to analyze discovered gas reservoirs and the factors that control gas accumulation and enrichment.

(iii) The scale, distribution, orientation, activity and phase of basement faults are all very important to reef and oolitic gas reservoirs. The paleogeography and paleoenvironment formed by early structural processes control the distribution, scale and macroscopic distribution pattern of reef and oolitic beach reservoirs. Accompanying basement fault activities, deep hot fluids are moved and charged upwards. This promotes the constructive diagenesis of reservoirs through such processes as dolomitization and corrosion, 
thereby having great significance in the formation and improvement of reef and oolitic reservoirs. Therefore, research on basement faults in terms of mechanisms of formation, distribution rules, diagenesis of carbonate reservoirs, and the charging of gas are required.

For guidance and help in the study and preparation of this paper, thanks are due to Chen Gengsheng, the Deputy Chief Geologist of PetroChina Southwest Oil and Gas Field Company, and Professor Wang Yigang of the Exploration and Production Research Institute. This work was supported by the National Basic Research Program of China (2007CB209500) and the National Special Program of Science and Technology in China (2008ZX05004).

1 Wang Y G, Hong H T, Xia M L, et al. Exploration of reef-beach gas reservoirs surrounding Permian and Triassic troughs in Sichuan Basin (in Chinese). Nat Gas Ind, 2008, 28: 22-27

2 Zhao W Z, Wang Z C, Li J M, et al. Natural gas resources of the sedimentary basins in China. Mar Petrol Geol, 2008, 25: 309-319

3 Ma Y S, Zhang S C, Guo T L, et al. Petroleum geology of the Puguang sour gas field in the Sichuan Basin, SW China. Mar Petrol Geol, 2008, 25: 357-370

4 Zhao W Z, Luo P, Chen G S, et al. Origin and reservoir rock characteristics of dolostones in the early Triassic Feixianguan formation, NE Sichuan basin, China: Significance for future gas exploration. J Petrol Geol, 2005, 28: 83-100

5 Zhai G M. Petroleum Geology of China (Vol.12) (in Chinese). Beijing: Petroleum Industry Press, 1992. 28-80

6 Li J, Xie Z Y, Dai J X, et al. Geochemistry and origin of sour gas accumulations in the northeastern Sichuan Basin, SW China. Org Geochem, 2005, 36: 1703-1716

7 Ma Y S, Mou C L, Tan Q Y, et al. Reef-bank features and their constraint to reservoirs of natural gas, from Permian Changxing Formation to Triassic Feixianguan Formation in Daxian-Xuanhan area of Sichuan Province, South China. Earth Sci Front, 2007, 14: 182-192

8 Jia C Z, Li B L, Zhang X Y, et al. Formation and evolution of the Chinese marine basins. Chinese Sci Bull, 2007, 52(zk1): 1-11

9 Huang J Z, Chen S J, Song J R, et al. Hydrocarbon source systems and formation of gas fields in Sichuan Basin. Sci China Ser D-Earth Sci, 1997, 40: 32-42

10 Zhang S C, Zhu G Y, Chen J P, et al. A discussion on gas sources of the Feixianguan Formation $\mathrm{H}_{2} \mathrm{~S}$-rich giant gas fields in the northeastern Sichuan Basin. Chinese Sci Bull, 2007, 52(zk1): 113-124

11 Liang D G, Guo T L, Chen J P, et al. Some progresses on studies of hydrocarbon generation and accumulation in marine sedimentary regions, Southern China (Part 1): Distribution of four suites of regional marine source rocks (in Chinese). Mar Oil Gas Geol, 2008, 13: 1-16

12 Zhang S C, Liang D G, Zhu G Y, et al. Fundamental geological elements for the occurrence of Chinese marine oil and gas accumulations. Chinese Sci Bull, 2007, 52(zk1): 28-43

13 Song Y, Xu Y C. Origin and identification of natural gases (in Chinese). Petrol Explor Dev, 2005, 32: 24-29

14 Dai J X, Zou C N, Zhang S C, et al. Discrimination of abiogenic and biogenic alkane gases. Sci China Ser D-Earth Sci, 2008, 51: 1737-1749
15 Liu W H, Sun M L, Xu Y C. An approach to noble-gas isotopic compositions in natural gases and gas-source tracing in the Ordos Basin, China. Chinese Sci Bull, 2002, 47: 489-493

16 Tian H, Xiao X M, Yang L G, et al. Pyrolysis of oil at high temperatures: Gas potentials, chemical and carbon isotopic signatures. Chinese Sci Bull, 2009, 54: 1217-1224

17 Pulikesi M, Nader M, Thilakavathi M, et al. Thermal cracking and combustion kinetics of asphaltenes derived from Fosterton oil. Fuel Process Technol, 2009, 90: 1286-1291

18 Wang L S, Chen S J, Yang J J, et al. Geochemistry characteristic of carboniferous gas accumulation in Eastern Sichuan Basin (in Chinese). Mar Oil Gas Geol, 2000, 5: 133-144

19 Zhang S C, Zhu G Y. Gas accumulation characteristics and exploration potential of marine sediments in Sichuan Basin (in Chinese). Acta Petrol Sin, 2006, 27: 1-8

20 Dai J X. Pool-forming period and gas sources of Weiyuan gasfield (in Chinese). Petrol Geol Exp, 2003, 25: 473-480

21 Wei G Q, Chen G S, Du S M, et al. Petroleum systems of the oldest gas field in China: Neoproterozoic gas pools in the Weiyuan gas field, Sichuan Basin. Mar Petrol Geol, 2008, 25: 371-386

22 Zhu G Y, Zhang S C, Liang Y B, et al. The genesis of $\mathrm{H}_{2} \mathrm{~S}$ in the Weiyuan Gas Field, Sichuan Basin and its evidence. Chinese Sci Bull, 2007, 52: 1394-1404

23 Wang T S, Geng A S, Sun Y G, et al. Geochemical characteristics of solid bitumen in reservoir and their implication for the origin of natural gas of Feixianguan Formation in Northeastern Sichuan Basin (in Chinese). Acta Sedimentol Sin, 2008, 26: 341-348

24 Liu W H, Chen M J, Guan P, et al. Ternary geochemical-tracing system in natural gas accumulation. Sci China Ser D-Earth Sci, 2007, 50: 1494-1503

25 Wang L Z, Dai T M, Peng P A. Experiment of the ${ }^{40} \mathrm{Ar} /{ }^{39} \mathrm{Ar}$ dating of authigenic illite in gas reservoirs. Chinese Sci Bull, 2004, 49(S1): 89-89

26 Yun J B, Wu H Y, Feng Z H, et al. $\mathrm{CO}_{2}$ gas emplacement age in the Songliao Basin: Insight from volcanic quartz ${ }^{40} \mathrm{Ar}-{ }^{39} \mathrm{Ar}$ stepwise crushing. Chinese Sci Bull, 2010, 55: 1795-1799

27 Cai X Y, Zhu Y M, Huang R C. Geochemical behaviors and origin of reservoir bitumen in Puguang gas pool (in Chinese). Oil Gas Geol, 2006, 27: 340-347

28 Thompson K F M. Gas condensate migration and oil fractionation in deltaic system. Mar Petrol Geol, 1988, 5: 237-246

29 Xiong Y Q, Zhang H Z, Geng X H, et al. Thermal cracking of n-octadecane and its geochemical significance. Chinese Sci Bull, 2004, 49(SI): 79-83

30 Isaksen G H. Central North Sea hydrocarbon systems: Generation, migration, entrapment, and thermal degradation of oil and gas. AAPG Bull, 2004, 88: 1545-1572

31 Zhao W Z, Wang Z C, Wang Y G, et al. Formation mechanism of highly effective gas pools in the Feixianguan Formation in the NE Sichuan basin (in Chinese). Geol Rev, 2006, 52: 708-717

32 Zeng Y X, Liu W. Research on structural evolution and oil/gas reservoiring of Feixianguan formation in Northwest Sichuan Basin (in Chinese). Nat Gas Ind, 2005, 25(SA): 21-23

33 Fan M, Hu K, Jiang X Q, et al. Effect of acid fluid on carbonate reservoir stimulation (in Chinese). Geochim, 2009, 38: 20-26

34 Huang S J, Qing H R, Hu Z W, et al. Diagenesis and dolomitization of the Feixianguan carbonates of Triassic in NE Sichuan Basin: An overview (in Chinese). Nat Gas Geosci, 2007, 22: 495-502

Open Access This article is distributed under the terms of the Creative Commons Attribution License which permits any use, distribution, and reproduction in any medium, provided the original author(s) and source are credited. 